\title{
Work Experience and Satisfaction among Beauty Graduates in Foreign Countries
}

\author{
Eun Young Jung ${ }^{1}$, Mee Young Park ${ }^{2 *}$ \\ ${ }^{1}$ Department of Beauty Art, Cheju Halla University, Jeju-si, Jeju-do, Korea \\ ${ }^{2}$ Department of Nursing, Cheju Halla University, Jeju-si, Jeju-do, Korea
}

*Corresponding author: Mee Young Park, Department of Nursing, Cheju Halla University, 38 Halladaehak-ro, Jeju-si, Jeju-do 63092, Korea

Tel.: +82 647417678

Fax: +82 647473989

Email: misty0128@chu.ac.kr

Received October 4, 2016

Revised February 3, 2017

Accepted February 13, 2017

Published March 30, 2017

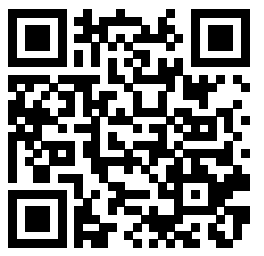

\begin{abstract}
Purpose: This study was conducted to investigate the status of beauty graduates working in foreign countries and identify the factors affecting the satisfaction/ dissatisfaction with regards to their work experiences in foreign countries. Methods: Target population of the study was beauty graduates from four Korean universities who are currently employed or have worked in foreign countries at least once. The response rate was $70 \%$, and 40 completed survey questionnaires were included in the final analysis. Results: The majority of respondents were women (92.5\%) aged less than 29 years (85.0\%). Of these, 70.0\% were skincare specialists and $22.5 \%$ were hair specialists, most of whom (92.5\%) worked in Australia and New Zealand. The main motivation was to experience foreign cultures $(82.5 \%)$ and $80.0 \%$ went out through their university support programs. Of the respondents, $82.5 \%$ worked at shops owned by Koreans and $55.0 \%$ worked from six months to one year and $27.5 \%$ worked over one year by the time of the survey. Furthermore, $42.5 \%$ of the respondents received pre-job training for six months or less and $35.0 \%$ received it for less than three months. Respondents agreed that their training period was appropriate. The majority (85.0\%) of respondents participated in some sort of language training and $75.0 \%$ said that their language training was most helpful. Foreign cultural experience and improvement in language skills were the factors that affected their satisfaction the most with regards to their work experiences in foreign countries. In contrast, dissatisfaction factors comprised the lack of welfare, including accommodation issues and low salary. Conclusion: The findings of this study are expected to be used as a basis to develop student training programs for those who wish to work in foreign countries.
\end{abstract}

Keywords: Beauty graduates, Foreign work experience, Pre-job training, Satisfaction, Language training

\section{Introduction}

국제화와 글로벌 지식경제 사회로의 진입에 발맞춰 국내 노동시 장과 청년실업의 한계를 극복하고자 고등교육 기관의 글로벌 인재 양성을 위한 노력이 한층 강화되었으며, 국제적 역량 계발을 위한 교육 및 훈련 프로그램의 운영이 전 세계적인 현상이 되고 있다(Kim $\& \mathrm{Kim}, 2014)$. 정부는 청년 실업문제를 해소하고 세계적인 안목을 가진 글로벌 인재를 양성하기 위한 전략으로 대학 졸업자들의 해외 취업을 적극 추진하고 있으며, 대학은 학생들에게 외국기업 등에서 다양한 문화를 경험할 수 있는 기회를 제공하고, 전공관련 업무지식
과 기술을 향상시켜 궁극적으로는 국 - 내외 취업을 촉진시킨다는 목 적으로 해외인턴쉽과 해외취업을 확대하고 있다(Lee, 2011).

해외취업은 한 국가의 노동력이 자기나라의 영토를 벗어나 외국 에서 경제적 수입을 목적으로 일정기간 고용되어 일하기 위해 자발 적인 의사에 따라 일시적으로 이동하는 현상을 의미하지만(Yoo et al., 2013), 국가 및 개인의 사정에 따라 현지에 정착하게 되는 경우 도 있어 해외취업이 해외이민으로 전환되는 계기가 된다. 세계 경 제의 침체로 인한 실업문제는 앞으로 단기간에 개선되기 어려울 전 망이며 국내 시장만을 대상으로 해결책을 찾는 데에는 한계가 있어 청년층의 해외취업진출을 통한 고용확대를 적극적으로 모색할 필 
요가 있다. 청년층의 해외취업진출은 중장기적으로 국가 경제발전 에 긍정적인 영향을 미치며, 해외와의 활발한 인적 교류를 통한 새 로운 기술의 획득, 해외 직장 경험 등으로 글로벌 인재 양성, 국제 적 네트워크 형성 등의 경제외적인 효과도 극대화할 수 있는 등 다 양한 이점이 있다. 그럼에도 불구하고 현재 청년 해외취업 프로그 램의 운영이 체계적이지 못하여 실질적인 성과는 기대만큼 높지 않 은 실정이다(Kwon \& Kim, 2011).

현대인들은 경제 수준의 향상과 더불어 문화적인 의식 수준도 크게 향상되어 내적인 미(美)와 외적인 미를 동시에 추구하고 있다. 최근에는 외적인 아름다움에 대해 더 큰 관심을 보이고 있어 이러 한 시대적 요구에 따라 미에 대한 가치 기준이 변화 - 발전되고 있 으며, 미를 창조하는 미용인의 업무 또한 전문화되고 세분화되어 가고 있다(Kang \& Rhee, 2014). 현대 사회는 뷰티를 좀 더 확장적 이고 주관적인 개념으로 받아들이고 있으며, 이러한 맥락에서 뷰티 산업도 화장품 산업에만 국한되는 것이 아니라 '인체를 아름답고 건강하게 관리하기 위해 서비스를 제공하는 산업'으로 정의되며 두 발미용, 피부미용, 메이크업, 네일아트 등의 미용 관련 산업을 포함 하고 있다(Chin, 2011).

미용업은 단순한 기술직이 아니라 전문지식과 섬세하고 숙련된 기술을 요하는 전문직종이며 고객과의 접촉을 통한 작업시간이 다 른 서비스업에 비해 장시간에 걸쳐 이루어지므로 인적자원의 역할 이나 비중이 상대적으로 크다(Jeon, 2008; Jung \& Park, 2015). 그 러나 일부 대기업을 제외하고는 국내 뷰티 산업계의 근무환경이 열 악한 상태이며, 전공관련 업무지식과 기술을 향상시킬 수 있는 기회 가 적어 대학의 지원을 통한 인턴쉽이나 해외취업을 확대할 필요성 이 크게 대두되고 있으며, 해외인력진출을 통해 일자리 창출 및 인 적 교류를 적극적으로 추진해야 한다는 주장이 설득력을 얻고 있다.

해외취업에 관한 선행연구는 치위생사와 치기공사의 해외취업
에 대한 선호도에 관한 연구(Kim \& Kim, 2012; Yoo et al., 2013), 해외취업 및 인턴쉽에 대한 인식 및 만족도에 관한 연구(Choi et al., 2009), 해외취업의 활성화 방안에 관한 연구(Cho et al., 2015; Kim, 2008; Kwon et al., 2011; Kwon \& Kim, 2011) 등이 있다. 이외 해외인턴쉽의 성공요인에 대한 분석(Lee, 2011), 병원간호사 의 해외취업 의향에 영향을 미치는 요인(Lee \& Son, 2010) 등이 보고되었다. 뷰티 분야의 해외취업 관련 연구로는 일본 고용시장 의 효율적인 접근방안(Jun, 2013)과 뷰티학과 학생들의 해외인턴 쉽 및 해외취업에 대한 인식과 취업준비 행동(Park, 2016) 등에 관 한 연구만이 진행된 상황이다. 위와 같이, 해외취업에 관한 선행연 구는 일부 취업군에 국한되어 있거나 해외취업군에 대한 취업 현황 이나 취업 후 전망에 대한 분석보다는 편의적 표본을 대상으로 하 는 해외취업에 대한 선호도 조사에 그치는 경향이 있고, 뷰티 분야 실제 해외취업자를 대상으로 한 연구는 전무한 실정이다.

따라서 본 연구의 목적은 뷰티를 전공한 해외취업자의 현황을 파악하고 만족도에 영향을 미치는 요인들을 조사하여 참가자들의 현실적 요구 등에 기반한 지원방안을 도출하기 위한 기초 자료를 마련하기 위함이다.

\section{Methods}

\section{1. 연구대상 및 자료수집방법}

본 연구는 국내 4 개 대학의 뷰티 전공 해외취업 참가자를 대상으 로 2016년 4월 부터 6월 까지 2개월간 실시하였으며, 설문 응답자 는 현재 해외취업 중이거나 1 회 이상 해외취업을 다녀온 경험이 있 는 대학 졸업자였다. 응답자가 연구설명문에 제시된 연구의 목적과 설문 내용을 읽고 설문에 응답하면 연구 참여에 동의한 것으로 간

Table 1. Demographics of respondents

\begin{tabular}{|c|c|c|c|}
\hline Categories & Items & $\mathrm{N}$ & $\%$ \\
\hline \multirow{2}{*}{ Gender } & Male & 3 & 7.5 \\
\hline & Female & 37 & 92.5 \\
\hline \multirow{2}{*}{ Age } & 29 and under & 34 & 85.0 \\
\hline & 30 and over & 6 & 15.0 \\
\hline \multirow{5}{*}{ Major subject } & Hair & 9 & 22.5 \\
\hline & Skincare & 28 & 70.0 \\
\hline & Makeup & 1 & 2.5 \\
\hline & Nail-art & 1 & 2.5 \\
\hline & Others & 1 & 2.5 \\
\hline \multirow{3}{*}{ Education } & Bachelor & 5 & 12.5 \\
\hline & Associate bachelor & 34 & 85.0 \\
\hline & Others & 1 & 2.5 \\
\hline \multirow{2}{*}{ Marriage status } & Never married & 33 & 82.5 \\
\hline & Married & 7 & 17.5 \\
\hline \multirow{2}{*}{ Countries worked in } & Australia, New Zealand & 37 & 92.5 \\
\hline & Asia including China and Japan & 3 & 7.5 \\
\hline
\end{tabular}


주됨을 미리 알려주었다. 총 배포된 60 부 중 42 부가 회수되어 응답 률은 $70 \%$ 를 기록하였고, 그 중 불성실 응답 설문지 2 부를 제외한 40 부가 최종 분석에 사용되었다.

\section{2. 연구도구}

연구도구인 자가응답형 설문지는 연구자가 문헌 고찰과 관련 분야 전문가와의 상담을 통해 최근 동향을 파악한 후 초안을 설계 하였고, 통계 전문가의 자문을 거쳐 최종 완성하였다. 설문지의 내용은 조사 대상자의 일반적인 사항을 비롯하여 해외취업을 하 게된 동기, 해외취업 현황, 해외취업을 하게된 경로, 해외취업을 위한 준비항목, 해외취업 수행에 대한 중요도와 만족도 등 총 48 문항으로 구성되었다.

\section{3. 통계처리}

본 연구를 위해 수집된 자료는 데이터 코딩(coding) 및 클리닝 (cleaning) 과정을 거쳐 Statistical Package for Social Science (SPSS) V.21 통계 패키지(IBM, USA)를 활용하여 분석하였다. 모든 문항은 빈도, 백분율을 활용하여 일차 분석되었고, Likert scale을 적용한 문항은 평균값과 표준편차를 구해 비교 분석하였다.

\section{Results and Discussion}

\section{1. 연구대상자의 일반적 특성}

연구대상자의 일반적 특성은 Table 1 과 같다. 성별은 남자가 $7.5 \%$, 여자가 $92.5 \%$ 로 뷰티 산업의 특성상 여자 응답자가 대다 수였고, 연령은 워킹홀리데이 비자 발급이 가능한 29세 이하가 $85.0 \%$ 로 가장 많았고 30 세 이상이 $15.0 \%$ 이었다. 응답자의 대학 전 공은 피부미용이 $70.0 \%$ 로 가장 많았고, 헤어가 $22.5 \%$, 메이크업이 $2.5 \%$, 네일아트 $2.5 \%$, 기타가 $2.5 \%$ 이었다. 최종학력은 전문대졸 이 $85.0 \%$ 로 가장 많았으며 $82.5 \%$ 가 미혼이었다. 해외 근무국가는 호주와 뉴질랜드가 $92.5 \%$ 로 대다수를 차지하였고 중국, 일본 등 아시아가 7.5\%이었다. Park (2016)의 연구에 의하면 뷰티학과 학 생들의 인턴쉽 및 취업 희망 국가는 북미(미국, 캐나다)가 가장 많 았고, 호주, 중국의 순이었으나 실제 뷰티 전공자의 해외근무지는 호주, 뉴질랜드가 대다수를 차지하여 희망국가와 실제 취업 및 인 턴쉽 국가는 차이가 있는 것으로 나타났다. 이는 현재 대부분의 대 학들이 졸업예정자를 대상으로 해외취업 및 인턴쉽을 진행하고 있 어 워킹홀리데이 비자 발급이 용이한 호주, 뉴질랜드 지역으로 집 중된 결과라 할 수 있다. 또한 미국, 캐나다 등 많은 국가에서 취업

Table 2. Employment status

$(\mathrm{N}=40)$

\begin{tabular}{|c|c|c|c|}
\hline Categories & Items & N & $\%$ \\
\hline \multirow{4}{*}{ Motivation } & Various foreign cultural experiences & 33 & 82.5 \\
\hline & Improving language skills & 3 & 7.5 \\
\hline & Learning advanced practical skills & 3 & 7.5 \\
\hline & Obtaining job experiences & 1 & 2.5 \\
\hline \multirow{5}{*}{ Supporting institution } & Through university support programs & 32 & 80.0 \\
\hline & Media & 0 & 0.0 \\
\hline & Human resources development service of Korea & 0 & 0.0 \\
\hline & Job recruitment company & 1 & 2.5 \\
\hline & Others & 7 & 17.5 \\
\hline \multirow{2}{*}{ Shop category by owner } & Korean owned & 33 & 82.5 \\
\hline & Locally owned & 7 & 17.5 \\
\hline \multirow{6}{*}{ Shop category by specialty } & Skincare shop & 23 & 57.5 \\
\hline & Hair shop & 8 & 20.0 \\
\hline & Wedding shop & 1 & 2.5 \\
\hline & Spa & 2 & 5.0 \\
\hline & Nail shop & 2 & 5.0 \\
\hline & Others & 4 & 10.0 \\
\hline \multirow{5}{*}{ Employment period } & Less than six months & 7 & 17.5 \\
\hline & Six months to less than one year & 22 & 55.0 \\
\hline & One year to less than two years & 9 & 22.5 \\
\hline & Two years to less than three years & 1 & 2.5 \\
\hline & Four years and over & 1 & 2.5 \\
\hline \multirow{4}{*}{ Monthly salary } & Less than $1,000,000$ won & 2 & 5.0 \\
\hline & $1,000,000$ to $2,000,000$ won & 28 & 70.0 \\
\hline & $2,000,000$ to $3,000,000$ won & 9 & 22.5 \\
\hline & $3,000,000$ won and over & 1 & 2.5 \\
\hline \multirow{3}{*}{ Visa category } & Working holiday visa & 33 & 82.5 \\
\hline & Student visa & 3 & 7.5 \\
\hline & Working visa & 4 & 10.0 \\
\hline
\end{tabular}


비자의 경우 학사학위 이상, 실무경력 2-3년 이상의 경력자를 우대 하고 있어 현지취업 및 인턴쉽을 위한 비자 발급이 어려운 현실이 반영되었다 할 수 있다.

\section{2. 근무상태}

응답자의 해외인턴쉽 지원동기는 다양한 해외문화체험이 $82.5 \%$ 로 가장 많았고 어학능력향상과 선진기술 습득이 각각 $7.5 \%$, 국내 취업 시 경력을 인정받기 위함이 $2.5 \%$ 로 가장 낮은 결과를 보였다 (Table 2). 이는 조리 및 외식관련 전공자를 대상으로 조사한 결과 선진문화 체험 및 견문확대, 해외선진실무기술 축적, 어학능력의 향상 순으로 나타난 Choi et al. (2009)의 연구결과와 유사하였다. 해외문화체험이나 어학능력이 주요 지원동기로 꼽힌 이유는, 국내 에 이미 4년제 및 2 년제 미용관련학과가 개설되어 체계적인 교육 시스템을 구축하고 있으며(Kang \& Choi, 2012), 국내 뷰티 기술에 대한 학생들의 자부심이 매우 높아 해외취업을 통해 선진기술을 습 득할 수 있다는 기대치가 낮기 때문이라고 할 수 있다. 또한, 실제 로 해외취업 경력이 국내 취업 시 전문분야 경력으로 인정되지 않 는 경향이 있어 경력인정에 대한 기대치도 낮음을 반영한 것이라 볼 수 있다. 그러나, 치위생사를 대상으로 한 Yoo et al. (2013)이 조 사한 연구에서는 해외취업의사가 있는 집단을 대상으로 조사한 경 우 주로 경제적 이득을 목적(35.99\%)으로 해외취업을 고민하고 있 었고, 그 다음이 자아실현(26.75\%), 업무의 질 향상 $(21.66 \%)$ 순으 로 나타나 본 연구와는 차이가 있었다.

응답자의 $80.0 \%$ 는 학교나 학과의 추천으로 졸업과 동시에 취업을 나간 경우였으며, $82.5 \%$ 가 한인 운영업체에서 근무한 것으로 나타났 다. 이는 전문기술 부족보다는 영어 등 현지 언어 능력의 부족으로 인 한 현지취업에 어려움이 있는 것으로 사료된다. Yoo et al. (2013)은 어 학능력 부족이 해외취업의 가장 큰 장애요소이므로 해외취업률 향상 을 위해 어학능력을 강화하는 것이 반드시 필요하다고 하였다.
해외취업 중 근무처는 피부관리실이 $57.5 \%$ 로 가장 많았고, 미용 실이 $20.0 \%$, 스파와 네일샵이 각각 $5.0 \%$ 등 이었다. 이는 최근 의 료뷰티 관광산업과 더불어 피부미용분야의 해외진출이 활성화되고 의료서비스와 미용서비스의 결합으로 피부미용이 고부가가치 창출 이 가능한 분야로 자리매김한 결과라 할 수 있다(Park, 2016).

해외취업 기간은 6 개월-1년이 $55.0 \%$ 로 가장 많았고, 1-2년이 $22.5 \%, 6$ 개월 이하가 $17.5 \%, 2-3$ 년과 4 년 이상이 각각 $2.5 \%$ 이었 다. 해외취업 기간 중 평균 월수입은 1-200만원이 $70.0 \%$ 로 대다 수를 차지하였고, 2-300만원이 $22.5 \%, 100$ 만원 이하가 $5.0 \%, 300$ 만원 이상이 $2.5 \%$ 이었다. Kwak \& Song (2014)의 연구결과에 의 하면 국내 뷰티 산업 종사자의 경우 급여 150 만원 이하가 $35.6 \%$, 150-200만원이 $20.2 \%$ 로 가장 많은 결과를 보여 국내 급여수준 과 해외현지 급여수준에 차이가 없는 것으로 나타났다. 이는 국내 의 최저시급이 지속적으로 상승한 결과이기도 하지만 해외현지에 서 한인업체에 주로 취업하고 있어 봉급수준이 타업종에 비해 낮 은 결과로 사료된다. 해외취업 중 비자상태는 워킹홀리데이 비자가 $82.5 \%$ 로 가장 많았고, 학생 비자가 $7.5 \%$ 이었으며 정식 워킹 비자 를 발급 받아 취업한 경우는 $10.0 \%$ 뿐이었다.

\section{3. 사전교육현황}

해외취업을 위해 받은 교육훈련기간은 6 개월 이하가 $42.5 \%$ 로 가장 많았고 3 개월 이하가 $35.0 \%$, 1 년 이상이 $2.5 \%$ 로 가장 낮은 결 과를 보였다(Table 3). 반면, 응답자들이 생각한 필요한 교육훈련 기간은 6 개월 이하가 $45.0 \%$ 로 가장 많았고 3 개월 이하가 $32.5 \%$ 로 나타나 실제 받은 기간과 유사하였으나 1년 이상의 장기 교육훈련 이 필요하다고 응답한 사람이 $22.5 \%$ 로 나타났다. 해외취업과 관련 하여 받은 교육은, 어학 중심교육이 $85.0 \%$ 로 가장 높았고, 직무중 심교육이 $47.5 \%$, 서비스매너교육 및 자격증과정이 $40.0 \%$, 현지문 화교육 $22.5 \%$ 의 순으로 나타났다. Kwon \& Kim (2011)은 어학교
Table 3. Pre-job training

\begin{tabular}{|c|c|c|c|}
\hline Categories & Items & $\mathrm{N}$ & $\%$ \\
\hline \multirow{5}{*}{ Received pre-job training period } & One month or less & 4 & 10.0 \\
\hline & Three months or less & 14 & 35.0 \\
\hline & Six months or less & 17 & 42.5 \\
\hline & One year or less & 4 & 10.0 \\
\hline & Over one year & 1 & 2.5 \\
\hline \multirow{5}{*}{ Recommended training period for respondents } & One month or less & 0 & 0.0 \\
\hline & Three months or less & 13 & 32.5 \\
\hline & Six months or less & 18 & 45.0 \\
\hline & One year or less & 0 & 0.0 \\
\hline & Over one year & 9 & 22.5 \\
\hline \multirow{5}{*}{ Types of pre-job training } & Language training & 34 & 85.0 \\
\hline & Practical skill training & 19 & 47.5 \\
\hline & Foreign cultural preparation & 9 & 22.5 \\
\hline & Service manner training & 16 & 40.0 \\
\hline & Obtaining licenses & 16 & 40.0 \\
\hline
\end{tabular}

$(\mathrm{N}=40)$ 
육의 경우 취업 시 즉시 사용할 수 있는 현장중심의 어학교육을 실 시하는 것이 필요하다고 하였으며, 해외취업 및 인턴쉽의 필요성과 함께 글로벌 마인드를 심어 주어 글로벌 시대에 맞는 현실에 대한 인식과 미래비전을 심어줄 필요가 있다고 하였다.

\section{4. 가장 도움이 된 사전교육}

응답자가 해외취업에 도움이 되었다고 밝힌 교육훈련 중 어학교 육이 1순위로 $60.0 \%$ 로 가장 많았고 직무교육이 $45.0 \%$, 산업체 현 장실습이 $27.5 \%$ 순이었다. 현지문화교육은 $12.5 \%$ 로 가장 낮은 결 과를 보였다(Table 4). 2순위로는 현지문화교육이 $27.5 \%$, 서비스매 너교육이 $20.0 \%$, 산업체 현장실습이 $17.5 \%$ 이었다. 전체 응답자의 75. $0 \%$ 가 어학교육이 해외취업에 도움이 된다고 선택하였고, $55.0 \%$ 가 직무교육, 응답자의 $52.5 \%$ 가 서비스매너교육을 선택하였다. 이는 해외인턴쉽 이수를 위한 가장 중요한 선수과목에 대한 설문에 외국어, 실무관련 교과목, 커뮤니케이션 기법 그리고 해외문화관 광 순으로 나타난 Kim (2008)의 연구와 유사한 결과이다.

\section{5. 직무수행시 가장 중요한 요소}

해외취업 시 업무 수행에 있어서 중요한 요소는 무엇인지를 5점
척도로 조사한 결과(Table 5), 전공실무가 $4.55 \pm 0.68$ 로 가장 중요 도가 높았고 급여소득이 $4.55 \pm 0.64$, 근무시간이 $4.35 \pm 0.70$, 산 업체 환경이 $4.33 \pm 0.83$ 의 순으로 나타났다. 이외 기숙사 등 복 지시설, 개인 발전을 위한 투자의 순이었으며 승진이 $3.78 \pm 0.92$ 로 가장 낮은 결과를 보였다. 뷰티의 경우 현지취업 시 가장 우선 되는 것이 실무기술이며 급여소득이나 근무시간, 산업체 근무환경 등의 중요도가 높게 나타났으며 이는 조리 외식전공자를 대상으로 한 해외취업 수행의 중요도에 관한 조사에서 언어(4.37), 부서간의 협력(4.30), 대인관계(4.21) 순으로 중요도가 높게 나타난 Choi et al. (2009)의 연구와는 다른 결과이다. 이는 뷰티 전공자들이 주로 취업 을 하는 현지 한인산업체들이 소규모인 경우가 대부분이고 직원이나 부서간의 협력 작업보다는 개인 작업을 주로 하는 뷰티업무의 특성 과 관련있다. 또한 산업체내 체계적인 승진시스템이나 직급체계가 구축되어 있지 않아 승진에 대한 기대치가 낮은 결과라 할 수 있다.

\section{6. 해외취업에 만족하는 이유}

해외취업과 관련하여 만족하는 이유를 복수 선택하게 하였을 때(Table 6), 해외 선진문화 체험의 기회에 대한 만족도가 $60.0 \%$ 로 가장 높았고, 외국어능력 향상이 $57.5 \%$, 선진실무기술 습득

Table 4. The most helpful pre-job training

$(\mathrm{N}=40)$

\begin{tabular}{|c|c|c|c|c|c|c|c|c|}
\hline \multirow{2}{*}{ Categories } & \multicolumn{2}{|c|}{ 1st priority } & \multicolumn{2}{|c|}{ 2nd priority } & \multicolumn{2}{|c|}{ 3rd priority } & \multicolumn{2}{|c|}{ Sum $^{1)}$} \\
\hline & $\mathrm{N}$ & $\%$ & $\mathrm{~N}$ & $\%$ & $\mathrm{~N}$ & $\%$ & $\mathrm{~N}$ & $\%$ \\
\hline Language training & 24 & 60.0 & 6 & 15.0 & 0 & 0.0 & 30 & 75.0 \\
\hline Practical skills training & 18 & 45.0 & 3 & 7.5 & 1 & 2.5 & 22 & 55.0 \\
\hline Foreign cultural preparation & 5 & 12.5 & 11 & 27.5 & 2 & 5.0 & 18 & 45.0 \\
\hline Service manner training & 10 & 25.0 & 8 & 20.0 & 3 & 7.5 & 21 & 52.5 \\
\hline Practicum at shops & 11 & 27.5 & 7 & 17.5 & 1 & 2.5 & 19 & 47.5 \\
\hline Obtaining licenses & 8 & 20.0 & 4 & 10.0 & 5 & 12.5 & 17 & 42.5 \\
\hline
\end{tabular}

${ }^{1)}$ Sum, total number and percentage of 1st, 2nd, and 3rd.

Table 5. Important factors influencing job performance

$(\mathrm{N}=\mathbf{4 0})$

\begin{tabular}{|c|c|c|c|c|c|c|c|c|c|c|c|c|}
\hline \multirow{2}{*}{ Categories } & \multicolumn{2}{|c|}{$\begin{array}{c}\text { Very } \\
\text { important }\end{array}$} & \multicolumn{2}{|c|}{ Important } & \multicolumn{2}{|c|}{ Neutral } & \multicolumn{2}{|c|}{$\begin{array}{c}\text { Less } \\
\text { important }\end{array}$} & \multicolumn{2}{|c|}{$\begin{array}{c}\text { Least } \\
\text { important }\end{array}$} & \multirow[t]{2}{*}{ Average } & \multirow[t]{2}{*}{$\mathrm{SD}^{1)}$} \\
\hline & $\mathrm{N}$ & $\%$ & $\mathrm{~N}$ & $\%$ & $\mathrm{~N}$ & $\%$ & $\mathrm{~N}$ & $\%$ & $\mathrm{~N}$ & $\%$ & & \\
\hline Practice relevance & 26 & 65.0 & 10 & 25.0 & 4 & 10.0 & 0 & 0.0 & 0 & 0.0 & 4.55 & 0.68 \\
\hline Size of shop (company) & 12 & 30.0 & 14 & 35.0 & 14 & 35.0 & 0 & 0.0 & 0 & 0.0 & 3.95 & 0.88 \\
\hline Work environment & 22 & 55.0 & 9 & 22.5 & 9 & 22.5 & 0 & 0.0 & 0 & 0.0 & 4.33 & 0.83 \\
\hline Work cooperation & 14 & 35.0 & 13 & 32.5 & 9 & 22.5 & 4 & 10.0 & 0 & 0.0 & 3.93 & 1.00 \\
\hline Working hours & 19 & 47.5 & 16 & 40.0 & 5 & 12.5 & 0 & 0.0 & 0 & 0.0 & 4.35 & 0.70 \\
\hline Personal development & 15 & 37.5 & 18 & 45.0 & 7 & 17.5 & 0 & 0.0 & 0 & 0.0 & 4.20 & 0.72 \\
\hline Salary & 25 & 62.5 & 12 & 30.0 & 3 & 7.5 & 0 & 0.0 & 0 & 0.0 & 4.55 & 0.64 \\
\hline Promotion & 9 & 22.5 & 17 & 42.5 & 10 & 25.0 & 4 & 10.0 & 0 & 0.0 & 3.78 & 0.92 \\
\hline Welfare (medical insurance etc.) & 13 & 32.5 & 17 & 42.5 & 6 & 15.0 & 4 & 10.0 & 0 & 0.0 & 3.98 & 0.95 \\
\hline Welfare (accommodation) & 16 & 40.0 & 16 & 40.0 & 8 & 20.0 & 0 & 0.0 & 0 & 0.0 & 4.20 & 0.76 \\
\hline
\end{tabular}

${ }^{1)} \mathrm{SD}$, standard deviation. 
이 $47.5 \%$ 로 그 다음이었다. 이는 해외취업 동기를 묻는 질문에서 (Table 2), 선진기술 습득이나 어학능력향상이 각 $7.5 \%$ 로 낮아 주 요 지원동기가 아니었던 것에 비하면 취업 후 매우 높아진 것으로 해외취업이 외국어능력 향상과 선진기술 습득의 기회를 제공하였 음을 의미한다고 볼 수 있다. 또한 봉급 등 경제적 보상이 $30.0 \%$, 해외이민의 기회 제공에 대한 만족도가 $25.0 \%$ 으로 나타나 해외취 업이 일정 정도 이민의 기회로 이어지고 있음을 나타낸다고 볼 수 있다. 해외 선진문화 체험의 기회에 대한 만족도가 가장 높은 것 은 해외인턴쉽 성과 변인 중 참여자 만족도에 통계적으로 유의한 수준으로 영향을 주는 변인은 '상관 및 동료와 적극적 의사소통' 요인과 ‘외국문화의 적극적 체험' 요인인 것으로 나타난 Bae et al. (2011)의 연구와 유사하다고 할 수 있다.

\section{7. 해외취업에 불만족한 이유}

해외취업과 관련하여 불만족한 이유를 복수 선택하게 하였을 때 (Table 7), 기숙사 등 복지제도의 부족이 $40.0 \%$ 로 높았으며 봉급 등 경제적 보상이 $32.5 \%$, 국내 취업 시 경력인정이 안됨이 $30.0 \%$ 로 그 다음이었다. 해외에서 취업 시 언어능력의 부족 등으로 한 인운영 산업체에 취업하는 경우가 대부분을 차지하여 기숙사 등 직원복지시설에 대한 지원이 부족하고 봉급수준도 현지 최저시급
기준에 미치지 못하는 경우가 있어 타업종 대비 근무조건이 떨어지 는 경우가 많은 것으로 파악된다. 또한 귀국 후 국내 산업체 취업 시 해외근무경력이 인정받지 못하는 경향이 있으며, 특히 헤어 전공인 경우 산업체에서 자체 승급제도를 통해 디자이너를 양성하고 있어 해외취업자의 경우 경력이 인정받지 못하는 경향이 있다. 해외취업 확대를 통한 글로벌 선진인력 양성을 위해 해외 현지의 우수한 취업 처 개발과 함께 산업체와 대학간의 협약을 통해 해외취업 경력을 적 극적으로 인정하는 방안을 마련하기 위한 노력이 이루어져야한다.

\section{Conclusion}

본 연구는 뷰티 전공자의 해외취업 실태를 조사하고자 설문조사 를 실시하였으며 조사 결과는 다음과 같다.

첫째, 조사대상자의 성별은 여자가 $92.5 \%$, 연령은 29 세 이하가 $85.0 \%$ 로 대부분을 차지하였다. 전공은 피부미용이 $70.0 \%$, 헤어미 용이 $22.5 \%$, 메이크업, 네일아트, 기타가 각 $2.5 \%$ 이었다. 해외근 무국가는 호주, 뉴질랜드가 $92.5 \%$ 로 대다수를 차지하였고, 중국, 일본 등 아시아가 $7.5 \%$ 이었다.

둘째, 해외취업의 지원동기는 다양한 해외문화체험이 $82.5 \%$ 로

Table 6. Factors influencing job satisfaction (multiple choices possible)

$(\mathrm{N}=40)$

\begin{tabular}{lcc}
\hline Categories & Agreed & N \\
\hline Learning advanced practical skills & 19 & 47.5 \\
\cline { 2 - 3 } Improving language skills & 23 & 57.5 \\
Economical gain (salary) & 12 & 30.0 \\
Opportunity for immigration & 10 & 25.0 \\
Good welfare (including accommodation) & 4 & 10.0 \\
Social perception regarding beauticians & 9 & 22.5 \\
Opportunity for foreign cultural experiences & 24 & 60.0 \\
Preferential treatment when getting a job in Korea & 4 & 10.0 \\
\hline
\end{tabular}

Table 7. Factors influencing job dissatisfaction (multiple choices possible)

\begin{tabular}{|c|c|c|}
\hline \multirow{2}{*}{ Categories } & \multicolumn{2}{|c|}{ Agreed } \\
\hline & N & $\%$ \\
\hline Lack of opportunity for learning advanced practical skills & 10 & 25.0 \\
\hline Lack of opportunity for improving language skills & 9 & 22.5 \\
\hline Low economical gain (salary) & 13 & 32.5 \\
\hline Lack of immigration opportunities & 6 & 15.0 \\
\hline Unsatisfactory welfare (including accommodation) & 16 & 40.0 \\
\hline Social perception regarding beauticians & 7 & 17.5 \\
\hline Cultural differences (racism) & 8 & 20.0 \\
\hline Work experience is not recognized when getting a job in Korea & 12 & 30.0 \\
\hline
\end{tabular}


가장 많았고, 지원기관은 학교 및 학과가 $80.0 \%$ 로 대다수를 차지 하였다. 해외 근무처는 한인 운영산업체가 $82.5 \%$ 이었고, 피부관 리실이 $57.5 \%$, 미용실이 $20.0 \%$ 이었다. 해외취업 기간은 6 개월 -1 년이 $55.0 \%$ 로 가장 많았고 1-2년이 $22.5 \%$ 이었다. 평균 월수입은 1-200만원이 $70.0 \%, 2-300$ 만원이 $22.5 \%$ 이었다. 해외취업 중 비 자상태는 워킹홀리데이 비자가 $82.5 \%$, 워킹비자가 $10.0 \%$ 이었다.

셋째, 해외취업을 위해 받은 교육훈련기간은 6 개월 이하가 $42.5 \%$ 로 가장 많았고 3 개월 이하가 $35.0 \%$ 이었다. 이는 응답자가 답한 해 외취업에 필요한 교육기간과 거의 일치하였다. 취업 전 $85.0 \%$ 가 어 학중심교육을 받았으며, 그 외 직무중심교육(47.5\%), 서비스매너교 육(40.0\%)과 자격증과정(40.0\%) 등을 받았다고 응답했다.

넷째, 해외취업에 가장 도움이 된 교육내용 중 1순위로 선정 된 항목은 어학교육(60.0\%), 직무교육(45.0\%), 산업체 현장실습 (27.5\%) 등 이었고, 2 순위는 현지문화교육(27.5\%), 서비스매너교 육 $(20.0 \%)$, 산업체 현장실습 $(17.5 \%)$ 등 이었다. 전체적으로는 응답 자의 $75.0 \%$ 가 어학교육이 가장 도움이 된다고 했으며, 직무교육 (55.0\%), 서비스매너교육 $(52.5 \%)$ 순이었다.

다섯째, 응답자가 답한 해외취업 시 업무 수행에 있어서 중요한 요소는 전공실무가 $4.55 \pm 0.68$ 로 가장 높았고, 급여소득이 $4.55 \pm$ 0.64 , 근무시간이 $4.35 \pm 0.70$, 산업체 환경이 $4.33 \pm 0.83$ 의 순으 로 나타났다. 이외 기숙사 등 복지시설, 개인 발전을 위한 투자의 순이었으며 승진이 $3.78 \pm 0.92$ 로 가장 낮은 결과를 보였다.

여섯째, 해외취업에 대해 만족하는 이유는 해외 선진문화 체험 $60.0 \%$, 외국어 능력 향상이 $57.5 \%$ 로 가장 높게 나타났고, 해외취 업에 불만족한 이유는 기숙사 등 복지제도가 $40.0 \%$ 로 가장 높았 고, 봉급 등 경제적 보상이 $32.5 \%$, 미용인에 대한 사회적 인식이 $17.5 \%$, 해외이민 등 기회제공 부족이 가장 낮은 $15.0 \%$ 로 나타났다.

본 연구는 기존의 해외취업 관련 연구가 대부분 취업 희망자를 대상으로 조사한 반면, 뷰티 전공자 중 해외취업을 하고 있거나 다 녀온 자를 대상으로 하여 실제 경험을 바탕으로 한 해외취업 실태 를 파악한 점에서 그 의의가 있다. 그러나 뷰티 전공 해외취업자가 현 시점에 많지 않고 졸업 후 소재 파악이 쉽지 않는 여건으로 인하 여, 연구대상이 한정적이어서 조사결과를 일반화 하기에는 무리가 있다. 향후 글로벌 역량 증진과 해외취업처 발굴 및 취업 증진을 위 해 전공별 해외취업 실태 조사 등 지속적인 연구를 통해 해외취업 자에게 필요한 어학교육 및 현지 직무능력교육 등의 다양한 프로그 램을 구축하여 제공하는 노력이 필요하다.

\section{References}

Bae SG, Lee H, Chung JY. Investigation into the influential factors on outcomes of college students' overseas internship. The Journal of Korean Education, 38: 289-
313, 2011.

Chin $\mathrm{CH}$. Status and prediction on beauty service industry in Korea. Asian Journal of Beauty and Cosmetology, 9: 179190, 2011.

Cho ES, Lee YD, Lee JG, Chung JS. Analysis on the overseas internship of Korean college students and policy implications. Journal of Employment and Career, 5: 1942, 2015.

Choi YH, Kim IS, Kim SY. Evaluation of the perception and satisfaction of working and internship abroad: by undergraduates studying in culinary and foodservice departments. Journal of the East Asian Society of Dietary Life, 19: 287-294, 2009.

Jeon SS. The effects of aesthetician's environment and satisfaction on professional consciousness. Asian Journal of Beauty and Cosmetology, 6: 19-27, 2008.

Jun YS. Effective approaches of hotel and beauty business in Japanese market. Journal of Japanese Culture, 56: 377399, 2013.

Jung EY, Park MY. Work patterns and job conditions of estheticians and nursing assistants working at the medical skincare area. Asian Journal of Beauty and Cosmetology, 13: 865-872, 2015.

Kang JA, Rhee YJ. A study on the relationship between achievement motivation and job performance of beauty industry professionals. Journal of the Korean Society of Cosmetology, 20: 1052-1059, 2014.

Kang SK, Choi KH. The analysis of domestic beauty-related school course and graduated beautician status. Journal of the Korean Society of Cosmetology, 18: 1393-1401, 2012.

Kim IS, Kim JS. A study on the preferences of dental technology students for overseas employment. The Journal of Korean Academy of Dental Technology, 34: 303-314, 2012.

Kim S, Kim Y. A study on educational programs and services improving professional capabilities for global employment of students in higher education. Journal of Educational Evaluation, 27: 783-807, 2014.

Kim YK. Extending employment opportunities for undergraduate female students at local universities through an international internship program. Korean Journal of Tourism Research, 22: 327-338, 2008.

Kwak KS, Song YS. The relation between the job satisfaction 
factors, degree of occupational satisfaction and turnover intention of hair beauty service industry workers in Korea. Journal of the Korean Society of Cosmetology, 20: 583589, 2014.

Kwon KD, Kang IK, Yim JB. A study on the improvement of oversea employment programs for young population. Korean Policy Sciences Review, 15: 361-392, 2011.

Kwon KD, Kim DJ. A study on the enhancement of oversea employment for young population. Korean Public Personnel Administration Review, 10: 201-230, 2011.

Lee EJ, Son JT. Factors influencing intention of migration by hospital nurses in Korea. Journal of Korean Academy of Nursing Administration, 16: 437-445, 2010.
Lee HW. Investigating factors of successful overseas internship program for nurturing global talent. The Korean Journal of Human Resource Development Quarterly, 13: 139-162, 2011.

Park SM. Beauty school students' perceptions of overseas internships and employment and their preparation behavior for employment: focusing on university or college women in Daegu. Journal of Investigative Cosmetology, 12: 185-195, 2016.

Yoo JH, Kim YJ, Noh HJ. Intention of overseas employment in Korean dental hygienists. Journal of Korean Society of Dental Hygiene, 13: 933-939, 2013. 


\section{국문초록}

\section{뷰티 전공자의 해외취업 실태 및 만족도에 미치는 요인}

정은영 ${ }^{1}$, 박미영 ${ }^{2 *}$

${ }^{1}$ 제주한라대학교 뷰티아트과, 제주도 제주시, 한국

${ }^{2}$ 제주한라대학교 간호학과, 제주도 제주시, 한국

목적: 본 연구의 목적은 뷰티를 전공한 해외취업자의 현황을 파악하고 만족도에 영향을 미치는 요인들을 조사하여 참가자들의 현실 적 요구 등에 기반한 지원방안을 도출하기 위한 기초 자료를 마련하기 위함이다. 방법: 국내 4 개 대학의 뷰티 전공 해외취업 참가자 를 대상으로 2016년 4월부터 2개월간 설문조사를 실시하였으며, 응답률은 $70 \%$ 를 기록하였고, 총 40부가 최종 분석에 사용되었다. 결과: 본 연구의 응답자의 대부분이 여자(92.5\%)이며, 29 세 이하(85.0\%)였다. 피부미용 전공(70.0\%)이 헤어미용(22.5\%) 전공자보 다 다수이었으며, 근무국가는 호주, 뉴질랜드가 $92.5 \%$ 로 대다수를 차지하였다. 주된 해외취업의 지원동기는 다양한 해외문화체험 (82.5\%)이었으며, 대부분(80.0\%)이 학교 및 학과의 지원을 통해 해외취업에 참여하게 되었다. 주로 한인 운영산업체(82.5\%)에 취업하 였으며, 취업기간은 6 개월 - 1 년 이하(55.0\%)가 가장 많았다. 해외취업을 위해 받은 교육훈련기간은 6 개월 이하가 $42.5 \%$ 로 가장 많았 다. 취업 전 $85.0 \%$ 가 어학중심교육을 받았으며, 응답자의 $60.0 \%$ 가 어학교육이 가장 도움이 되었다고 답하여 취업 전 충분한 어학준비 의 필요성이 강조되었다. 해외취업 시 업무 수행에 있어서 전공실무능력(4.55 \pm 0.68$)$ 이 가장 중요한 요소로 꼽혔으며, 해외 선진문화 체험(60.0\%)과 외국어 능력 향상(57.5\%)의 기회가 만족도와 연결되었다. 결론: 본 연구는 기존의 해외취업 관련 연구가 대부분 취업 희망자를 대상으로 조사한 반면, 뷰티 전공자 중 해외취업을 하고 있거나 다녀온 자를 대상으로 하여 실제 경험을 바탕으로 한 해외취 업 실태를 파악한 점에서 그 의의가 있다. 향후 지속적인 연구를 통해 해외취업자에게 필요한 어학 및 현지직무능력 교육 등의 다양한 프로그램이 구축되어야 할 것이다.

핵심어: 뷰티 전공자, 해외취업 경험, 취업준비 훈련, 만족도, 어학교육

\section{참고문헌}

강수경, 최근희. 국내 대학의 미용관련학과 및 인력 배출 현황 분석. 한국미용학회지, 18: 1393-1401, 2012. 강주아, 이영주. 미용업 종사자의 성취동기와 직무성과의 관계 연구. 한국미용학회지, 20: 1052-1059, 2014.

곽기숙, 송연숙. 한국 헤어미용 서비스산업 종사자들의 직무만족요인과 직업만족도 및 이직의도와의 관계. 한국미용학회지,

20: 583-589, 2014.

권경득, 강일규, 임정빈. 해외취업의 활성화 방안에 관한 연구: 청년 해외취업을 중심으로. 한국정책과학학회보, $15: 361-$

392, 2011.

권경득, 김덕준. 청년 인적자원의 해외취업 활성화 방안에 관한 연구: 인식조사를 중심으로. 한국인사행정학회보, 10: 201-

230, 2011.

김신영, 김용련. 대학의 글로벌 인재 양성 및 해외취업 활성화를 위한 교육프로그램의 현황 분석 연구. 교육평가연구, 27 :

783-807, 2014.

김영규. 해외인턴십을 활용한 지방 4년제 대학 여성인력의 취업 활성화 방안. 관광연구, 22: 327-338, 2008.

김임선, 김정숙. 치기공과 학생들의 해외취업에 대한 선호도 조사. 대한치과기공학회지, 34: 303-314, 2012.

박선민. 뷰티학과 학생들의 해외인턴십 및 해외취업에 대한 인식과 취업준비 행동: 대구소재 여대생을 중심으로. 대한미용학

회지, 12: 185-195, 2016.

배성근, 이희숙, 정제영. 대학생 해외 인턴십 성과에 대한 영향 요인 분석. 한국교육, 38: 289-313, 2011.

유자혜, 김영진, 노희진. 치과위생사의 해외취업의사에 영향을 미치는 요인. 한국치위생학회지, 13: 933-939, 2013. 
이은주, 손정태. 병원간호사의 해외취업 의향에 영향을 미치는 요인. 간호행정학회지, 16: 437-445, 2010. 이황원. 글로벌 인재 양성을 위한 대학생 해외인턴십의 성공요인 분석. $H R D$ 연구, 13: 139-162, 2011.

전승신. 피부관리사의 직무환경과 직무만족도가 직업의식에 미치는 영향. 아시안뷰티화장품학술지, 6: 19-27, 2008. 전윤선. 호텔·뷰티 분야를 중심으로 일본 고용시장의 효율적인 접근방안. 일본문화학보, 56: 377-399, 2013.

정은영, 박미영. 피부미용사의 간호조무사 자격 취득에 따른 업무실태 조사. 아시안뷰티화장품학술지, 13: 865-872, 2015. 조은상, 이영대, 이종구, 정지선. 한국 대학생들의 해외 인턴쉽 활성화를 위한 탐색적 연구. 취업진로연구, 5: 19-42, 2015. 진정화. 한국 뷰티서비스 산업의 현황과 예측. 아시안뷰티화장품학술지, 9: 179-190, 2011.

최영희, 김일순, 김수연. 해외 취업 및 인턴쉽에 대한 인식과 만족도에 관한 연구. 동아시아식생활학회지, 19: 287-294, 2009. 


\section{中文摘要}

\section{美容专业毕业生的海外就业实况及满意度因素}

鄭恩英 ${ }^{1}$, 朴美英 $^{2 *}$

1濟州漢拏大學美容學科，濟州島濟州市，韩国

濟州漢拏大學看護學科，濟州島濟州市，韩国

目的: 调查美容专业毕业生的海外就业情况, 并确定海外就业满意度影响因素, 最终导出应答者的现实要求为基础的支援 方案, 提出基础资料。方法: 以四所韩国大学的美容毕业生为研究对象, 从2016年4月开始进行为期 2 个月的问卷调查, 回 答者中包含至少有在国外工作过一次的经历或目前在国外工作。回答率为 $70 \%$, 最终对 40 份问卷调查进行分析。结果: 大 多数应答者为女性占 $92.5 \%$ ，其中年龄小于 29 岁占 $85.0 \%$ 。皮肤美容专攻（70.0\%）多于美发专攻（22.5\%），其中大部分 (92.5\%) 在澳大利亚和新西兰工作。海外就业的主要动机是体验外国文化，大部分毕业生（80.0\%）是通过学校以及学科 的支援参加海外就业。在海外主要工作地点为韩国人运营的产业，占 $82.5 \%$, 就业期间为 6 个月到1年以下占 $55.0 \%, 1$ 年以上 占 $27.5 \%$ 。此外，为了在海外就业，42.5\%的大多数应答者接受岗前培训，其期间为6个月或更少，35.0\%的应答者不到 3 个 月。这个调查结果与应答者答复的海外就业培训期间一致。大多数（85.0\%）的应答者参加了语言培训，其中 $60.0 \%$ 的应答 者回答语言培训最有帮助, 强调了就业前语言培训的必要性。海外就业时, 专攻实务能力为最重要的因素。外国文化经验 (60.0\%)和语言技能的提高 (57.5\%)与海外工作经验满意度因素相关。与此相反, 不满因素大多数 (40.0\%) 与住宿等缺乏 福利相关, 其次为低工资 (32.5\%) 等经济问题。结论: 本次研究如同其他海外就业相关研究, 以求职者为研究对象, 同时 在美容专业者中以以前工作过或目前在海外工作为研究对象, 以实际经验为基础调查了海外就业状况, 这种调查显示重大意 义。未来通过持续的研究对海外就业者提供必要的语言及职能教育。

关键词: 美容专业者，海外就业经验，岗前培训，满意度，语言教育 